\title{
Improvement of Skeletal Muscle Regeneration by Platelet-Rich Plasma in Rats with Experimental Chronic Hyperglycemia
}

\author{
Raed Rtail $\mathbb{D}^{1},{ }^{1}$ Olena Maksymova, ${ }^{1}$ Viacheslav Illiashenko, ${ }^{1}$ Olena Gortynska, ${ }^{2}$ \\ Oleksii Korenkov, ${ }^{1}$ Pavlo Moskalenko, ${ }^{3}$ Mohamad Nasser, ${ }^{4}$ and Gennadii Tkach ${ }^{1}$ \\ ${ }^{1}$ Department of Morphology, Sumy State University, Sumy, Ukraine \\ ${ }^{2}$ Department of Family Medicine with Dermatovenerology, Sumy State University, Sumy, Ukraine \\ ${ }^{3}$ Department of Dentistry, Sumy State University, Sumy, Ukraine \\ ${ }^{4}$ Lebanese University, Hadath, Lebanon \\ Correspondence should be addressed to Raed Rtail; stat_bigdata@ukr.net
}

Received 18 March 2020; Revised 5 June 2020; Accepted 2 July 2020; Published 13 July 2020

Academic Editor: Cem Kopuz

Copyright (c) 2020 Raed Rtail et al. This is an open access article distributed under the Creative Commons Attribution License, which permits unrestricted use, distribution, and reproduction in any medium, provided the original work is properly cited.

Herein, the structural effect of autologous platelet-rich plasma (PRP) on posttraumatic skeletal muscle regeneration in rats with chronic hyperglycemia $(\mathrm{CH})$ was tested. 130 white laboratory male rats divided into four groups (I—control; II—rats with $\mathrm{CH}$; III-rats with $\mathrm{CH}$ and PRP treatment; and IV-rats for $\mathrm{CH}$ confirmation) were used for the experiment. $\mathrm{CH}$ was simulated by streptozotocin and nicotinic acid administration. Triceps surae muscle injury was reproduced by transverse linear incision. Autologous PRP was used in order to correct the possible negative $\mathrm{CH}$ effect on skeletal muscle recovery. On the 28 th day after the injury, the regenerating muscle fiber and blood vessel number in the $\mathrm{CH}+\mathrm{PRP}$ group were higher than those in the $\mathrm{CH}$ rats. However, the connective tissue area in the $\mathrm{CH}$ group was larger than that in the $\mathrm{CH}+\mathrm{PRP}$ animals. The amount of agranulocytes in the regenerating muscle of the $\mathrm{CH}$ rats was lower compared to that of the $\mathrm{CH}+\mathrm{PRP}$ group. The histological analysis of skeletal muscle recovery in $\mathrm{CH}+\mathrm{PRP}$ animals revealed more intensive neoangiogenesis compared to that in the $\mathrm{CH}$ group. Herewith, the massive connective tissue development and inflammation signs were observed within the skeletal muscle of $\mathrm{CH}$ rats. Obtained results suggest that streptozotocin-induced $\mathrm{CH}$ has a negative effect on posttraumatic skeletal muscle regeneration, contributing to massive connective tissue development. The autologous PRP injection promotes muscle recovery process in rats with $\mathrm{CH}$, shifting it away from fibrosis toward the complete muscular organ repair.

\section{Introduction}

Skeletal muscle injuries account for about $30 \%$ of all occupational diseases in industrialized countries [1]. Muscle trauma is also one of the main reasons for the decline of athlete competition performance [2]. Therefore, uncovering the cellular and molecular mechanisms of skeletal muscle regeneration and the development of effective ways of muscle recovery improvement are the important tasks of modern medical science [3].

Currently, chronic hyperglycemia $(\mathrm{CH})$ is one of the most common metabolic disorders worldwide [4]. $\mathrm{CH}$ is associated with the development of secondary complications in skeletal muscle and may impair its regeneration capacity. Experimental studies have shown that $\mathrm{CH}$ attenuates the expression of muscle-specific transcription factors (MyoD and myogenin) [5] and reduces the number of myosatellite cells (MSCs) in both animal and human skeletal muscle $[6,7]$. Jeong et al. have shown that MSCs derived from rats with streptozotocin-induced diabetes mellitus (DM) are incapable of myotube formation [8]. Also, rats with genetic DM models have a significant delay and incompleteness of posttraumatic skeletal muscle regeneration $[9,10]$.

Platelet-rich plasma (PRP) is one of the promising therapeutic agents capable of enhancing regeneration of various tissues and organs, including striated muscles. Wright-Carpenter et al. [11] revealed that autologous conditioned serum administration promotes MSC activation and increases the size of the regenerating fibers within injured skeletal muscle. Gigante et al. [12] had found that platelet- 
rich fibrin matrix improves regeneration and promotes neovascularization in striated muscle after mechanical lesion. Several studies have also shown that PRP administration reduces the regeneration time and improves histologic outcome and functional recovery of the skeletal muscle [13-16].

Hamid et al. [17] showed that PRP is able to accelerate the recovery of injured skeletal muscle in athletes. NiteckaBuchta et al. [18] have reported that PRP injection into the masseter muscle reduces pain in patients with temporomandibular disorders. However, a few systematic reviews have failed to conclude on PRP effectiveness and safety for human muscular injury treatments [19-21].

PRP does have a positive effect on soft tissue repair in patients with DM. The results of meta-analysis have shown that PRP significantly improves wound healing and accelerates functional recovery in patients with diabetic foot syndrome [22-24]. Regrettably, there is no current work devoted to investigation of the PRP effect on skeletal muscle regeneration under $\mathrm{CH}$ influence.

The aim of the study was to investigate the structural effects of autologous PRP on posttraumatic skeletal muscle regeneration in rats with $\mathrm{CH}$.

\section{Materials and Methods}

2.1. Animals. 130 white laboratory male rats (age-7-9 months) were used for the experiment. All the animals were divided into four groups: I-control group (40 rats with skeletal muscle injury); II- $\mathrm{CH}$ group (40 animals with simulated $\mathrm{CH}$ and skeletal muscle injury); III-CH+PRP group (40 rats with simulated $\mathrm{CH}$ and skeletal muscle injury, which received PRP injection into muscle damage area); and IV- $\mathrm{CH}$ confirmation group (10 animals with $\mathrm{CH}$ for glucose homeostasis evaluation).

All the animals, participating in the test, were examined for motor activity and outer covering condition. Then, rats were subjected to a two-week quarantine. The experimental animals were used according to policies of general ethical principles of experiments on animals (Kyiv 2001), Declaration of Helsinki (2000), European Convention for the Protection of Vertebrate Animals used for Experimental and Other Scientific Purposes (Strasbourg 1985). Ethics and morality were not violated during the research. Rats were housed in the vivarium room under constant temperature $\left(24-25^{\circ} \mathrm{C}\right)$, humidity $(60 \pm 5) \%$, and 12-hour dark-light cycle. Cage cleaning was performed daily.

\subsection{Simulation of Chronic Hyperglycemia and Muscle} Trauma. The rats of II, III, and IV groups have been consuming $10 \%$ aqueous fructose solution instead of drinking water for 2 weeks. Then, a single intraperitoneal injection of streptozotocin ( $40 \mathrm{mg} / \mathrm{kg}$, Sigma-Aldrich, USA), dissolved in citrate buffer ( $\mathrm{pH} 4.5)$, and nicotinic acid $(1 \mathrm{mg} / \mathrm{kg})$ for each animal was performed. Each control rat received a single intraperitoneal citrate buffer ( $\mathrm{pH} 4.5)$ injection. Following streptozotocin or vehicle administration, animals were placed under normal vivarium conditions with a normal diet (food and water ad libitum) for 60 days.
Animals of the IV group were used to assess glucose homeostasis and to confirm the $\mathrm{CH}$. Fasting glucose level, insulin, and C-peptide concentration were determined in the blood of these rats on the 60th day after $\mathrm{CH}$ simulation. Obtained data were used to confirm the $\mathrm{CH}$ presence.

2.3. Skeletal Muscle Injury. The injury model was modified from a rat model described by Tsai et al. [16]. The trauma of triceps surae muscle was reproduced in rats of I, II, and III groups 60 days after $\mathrm{CH}$ simulation. Surgery was performed in aseptic conditions under ketamine $(8 \mathrm{mg} / \mathrm{kg})$ and xylazine $(3 \mathrm{mg} / \mathrm{kg})$ anesthesia. The mechanical injury was applied by transverse linear incision of a lateral head of the triceps surae muscle at a point that is $40 \%$ distal to its origin. Ophthalmic knife (blade width-1.8 mm; blade length $-4.5 \mathrm{~mm}$ ) was used for traumatization. The defect width was approximately $75 \%$ of the muscle width; the defect depth was approximately $50 \%$ of the muscle thickness. At the end of the operation, the wound edges were matched and the skin was sutured.

2.4. PRP Preparation. A recent study showed that PRP promotes muscle regeneration and decreases inflammation and apoptosis in the injury model described above [16]. This allowed us to move forward and evaluate the effects of PRP on muscle recovery in rats with this injury model in the context of $\mathrm{CH}$. In order to correct a possible negative $\mathrm{CH}$ effect on skeletal muscle regeneration, the autologous PRP $(250 \mu \mathrm{l})$ was injected into the wound of III group animals before the suturing. Previously, $0.8 \mathrm{ml}$ of blood from the lateral tail vein was collected into vacutainers containing sodium citrate solution. The lost blood volume was immediately restored by sterile saline infusion. The selected blood was centrifuged $(20 \mathrm{~min}$; speed $-2,000 \mathrm{rpm})$. As a result, two blood component fractions were observed in the test tube: lower dark red fraction (cellular components) and an upper straw yellow fraction (serum components). The upper fraction and upper portion of the lower fraction were pipetted and transferred to another tube. The resulting material was centrifuged ( $15 \mathrm{~min}$; speed $-2,000 \mathrm{rpm})$, which led to the formation of two fractions: lower, platelet-rich plasma, and upper, platelet-poor plasma. The lower fraction was transferred to a sterile tube, and the volume was adjusted to $0.5 \mathrm{ml}$ with $10 \%$ calcium chloride solution [25]. The resulting solution was injected into the muscle wounds of III group animals. Each animal received its own (autologous) plasma.

2.5. Histology and Morphometry. The morphological features of skeletal muscle regeneration in I, II, and III groups were studied on the $3 \mathrm{rd}, 7 \mathrm{th}, 14 \mathrm{th}$, and 28 th day after receiving the mechanical injury. Animals were removed from the experiment (10 rats per term) by thiopental anesthesia overdose ( $4 \mathrm{mg} / 100 \mathrm{~g}$ body weight).

The portions of injured skeletal muscles were fixed in a $10 \%$ formalin solution in order to study the microscopic structure. The samples were dehydrated in alcohols of increasing concentration and then placed into paraffin. Transverse sections (across the muscle fibers) were made using MC-2 microtome (thickness-4-6 $\mu \mathrm{m}$ ). The staining 
was performed with hematoxylin-eosin (to evaluate the number and cross-sectional area of different muscle fibers, to determine vessel number, and to assess the inflammatory infiltration) and picrosirius red (to evaluate the collagen content and its formation dynamics). Semithin sections (thickness $-1 \mu \mathrm{m}$ ) stained with methylene blue were also made to visualize and count different white blood cells. The lateral head of triceps surae muscle sampling in each group was performed on all 10 rats.

An Olympus BH-2 microscope (Japan) was used for light microscopy. Images of histological specimens were performed using a Baumer/Optronic Typ: CX 05c digital camera. The morphometric analysis was done using microgrid, microwave line, and Digimizer computing software (version 5.3.5). All muscle fibers were divided into three types: normal muscle fibers (NMF)-typical muscle fibers without injury signs; damaged muscle fibers (DMF) - fibers with atypical shape and size along with signs of damage; and regenerating muscle fibers (RMF) - centrally nucleated fibers. Two-dimensional analysis of cross-sectional samples was carried out to determine the number of DMF (no. $/ \mathrm{mm}^{2}$ ), RMF (no. $/ \mathrm{mm}^{2}$ ), vessels (no./field), the regeneration area, the connective tissue area, granulocyte (no. $/ \mathrm{mm}^{2}$ ), and agranulocyte number $\left(\right.$ no. $/ \mathrm{mm}^{2}$ ). The regeneration area was calculated as the percentage of regenerating fibers from the total muscle fiber area. Connective tissue area was defined as the percentage of connective tissue area of the total muscle cross-sectional area. The qualitative summary assessment of the following histopathological changes was also carried out: necrosis (muscle fibers with impaired membrane integrity, vacuolization, and sarcoplasm disorganization); connective tissue edema (increasing of connective tissue spaces without signs of new fiber formation); inflammatory infiltration (amount of white blood cells); vascularization (number of vessels); fibrosis (area of new collagen fibers); and a number of centrally nucleated muscle fibers.

2.6. Statistical Analysis. Mathematical analysis was performed using SPSS (version 17.0, USA). Continuous data are presented as mean $(\mathrm{M}) \pm$ standard deviation (SD). KolmogorovSmirnov test was used to check the normality distribution. The significance of differences between groups was determined using Student's $t$-criterion and one-way ANOVA followed by Bonferroni post hoc test. $P$ values $<0.05$ were considered statistically significant.

\section{Results}

The results of blood biochemical analysis of control (group I) and experimental animals (group IV) on the 60th day after $\mathrm{CH}$ simulation are shown in Table 1. Rats with streptozotocin-induced $\mathrm{CH}$ had significantly higher fasting glucose level $(P<0.001)$ and decreased insulin content $(P=0.005)$. The $\mathrm{C}$-peptide amount did not differ between comparison groups $(P=0.267)$. $\mathrm{CH}$ rats also had higher concentration of total cholesterol $(P<0.001)$, triglycerides $(P<0.001)$, and LDL $(P<0.001)$ and decreased HDL level $(P=0.004)$. Obtained changes largely correspond to the type $2 \mathrm{DM}$ phenotype.
TABLE 1: The blood biochemical test of control and experimental rats.

\begin{tabular}{lccc}
\hline Parameter & $\begin{array}{c}\text { Control } \\
(n=10)\end{array}$ & $\mathrm{CH}(n=10)$ & $P$ \\
\hline Fasting glucose $(\mathrm{mmol} / \mathrm{l})$ & $4.97 \pm 0.73$ & $14.76 \pm 1.87$ & $<0.001$ \\
Total cholesterol $(\mathrm{mmol} / \mathrm{l})$ & $1.89 \pm 0.21$ & $3.26 \pm 0.36$ & $<0.001$ \\
Triglycerides $(\mathrm{mmol} / \mathrm{l})$ & $0.54 \pm 0.11$ & $1.03 \pm 0.16$ & $<0.001$ \\
LDL $(\mathrm{mmol} / \mathrm{l})$ & $0.59 \pm 0.08$ & $0.93 \pm 0.12$ & $<0.001$ \\
HDL $(\mathrm{mmol} / \mathrm{l})$ & $1.92 \pm 0.20$ & $1.48 \pm 0.21$ & 0.004 \\
Insulin $(\mu \mathrm{MU} / \mathrm{ml})$ & $16.01 \pm 1.81$ & $12.35 \pm 1.77$ & 0.005 \\
C-peptide $(\mathrm{ng} / \mathrm{ml})$ & $3.47 \pm 0.79$ & $3.96 \pm 0.64$ & 0.267 \\
\hline
\end{tabular}

LDL: low-density lipoproteins; HDL: high-density lipoproteins; $\mathrm{CH}$ : experimental chronic hyperglycemia. Data are presented as means \pm SD.

The results of estimating the muscle fibers and vessel amount in skeletal muscle of different groups on $3 \mathrm{rd}, 7 \mathrm{th}$, 14th, and 28th days after mechanical injury are presented in Table 2. The significant difference in the mean values of all studied parameters between rats of I, II, and III groups was revealed at each experiment time (according to ANOVA). The results of post hoc test on the 28th day after injury showed that DMF number in control rats was lower compared to that in $\mathrm{CH}$ (by $68.4 \%$; $P<0.001$ ) and $\mathrm{CH}+\mathrm{PRP}$ group (by 53.8\%; $P<0.001$ ). DMF number in animals with $\mathrm{CH}$ was higher than that in $\mathrm{CH}+\mathrm{PRP}$ rats (by $31.6 \% ; P<0.001$ ). In contrast, the $\mathrm{RMF}$ and blood vessel number on the 28th day after injury in control animals was higher compared to that in $\mathrm{CH}$ rats (by 26.8\%; $P<0.001$-for RMF; by $40 \% ; P<0.001$ - for vessels) and $\mathrm{CH}+\mathrm{PRP}$ rats (by 7.9\%; $P=0.030$-for $\mathrm{RMF}$; by $7.4 \%$; $P=0.041$-for vessels). The RMF (by $20.5 \% ; P<0.001$ ) and blood vessel (by 35.2\%; $P<0.001$ ) amount in the $\mathrm{CH}+\mathrm{PRP}$ group was higher than that in the $\mathrm{CH}$ group.

The morphometric analysis also included calculations on the area of regeneration and connective tissue (Figure 1). The regeneration area in rats with $\mathrm{CH}$ was significantly smaller compared to that in control animals (by $60.8 \% ; P<0.001$ -on the 14th day; by $32.6 \%: P<0.001$ - on the 28th day) and the $\mathrm{CH}+\mathrm{PRP}$ group (by $50.7 \% ; P<0.001-$ on the 14 th day; by $22.6 \% ; P<0.001-$ on the 28 th day). A significant difference in connective tissue area was revealed only on the 28th day after muscle lesion. Thus, the connective tissue area in the $\mathrm{CH}$ group was larger than that in control rats (by $15.6 \% ; P=0.014$ ) and $\mathrm{CH}+\mathrm{PRP}$ animals (by 22.1\%; $P=0.001)$.

One of the key components of successful skeletal muscle regeneration is the quality and proper sequence of inflammation development. Thence, the granulocyte and agranulocyte numbers in regenerating muscle were calculated (Figure 2). During the whole period of muscle recovery, the granulocyte amount was found to be significantly higher in rats with $\mathrm{CH}$ compared to control and $\mathrm{CH}+\mathrm{PRP}$ group $(P<0.05)$. In contrast, the agranulocyte content in $\mathrm{CH}$ rats was lower than that in control animals and $\mathrm{CH}+\mathrm{PRP}$ rats $(P<0.05)$.

The results of histological analysis in all studied groups are shown in Figure 3. The pronounced muscle fiber necrosis, 
TABLE 2: The number of muscle fibers and vessels in the injured skeletal muscle.

\begin{tabular}{|c|c|c|c|c|c|}
\hline Parameter & Group & 3 days & 7 days & 14 days & 28 days \\
\hline \multirow{4}{*}{ Damaged fibers (no./mm²) } & Control & $210.4 \pm 15.9$ & $202.7 \pm 23.7$ & $197.2 \pm 12.9$ & $47.4 \pm 3.5$ \\
\hline & $\mathrm{CH}$ & $227.4 \pm 14.6$ & $225.4 \pm 14.1$ & $283.3 \pm 18.9$ & $150.1 \pm 14.1$ \\
\hline & $\mathrm{CH}+\mathrm{PRP}$ & $212.8 \pm 12.9$ & $193.8 \pm 21.7$ & $206.0 \pm 32.7$ & $102.6 \pm 4.6$ \\
\hline & $\mathrm{P}$ & 0.030 & 0.005 & $<0.001$ & $<0.001$ \\
\hline \multirow{4}{*}{ Regenerating fibers (no. $/ \mathrm{mm}^{2}$ ) } & Control & - & $22.5 \pm 2.8$ & $211.5 \pm 14.1$ & $512.3 \pm 38.8$ \\
\hline & $\mathrm{CH}$ & - & $5.9 \pm 0.3$ & $92.9 \pm 6.2$ & $375.0 \pm 35.2$ \\
\hline & $\mathrm{CH}+\mathrm{PRP}$ & - & $15.7 \pm 1.8$ & $170.2 \pm 26.9$ & $471.9 \pm 21.2$ \\
\hline & $\mathrm{P}$ & - & $<0.001$ & $<0.001$ & $<0.001$ \\
\hline \multirow{4}{*}{ Vessels, (no./field) } & Control & $10.7 \pm 0.8$ & $11.2 \pm 1.5$ & $19.2 \pm 1.4$ & $27.0 \pm 2.1$ \\
\hline & $\mathrm{CH}$ & $7.5 \pm 0.5$ & $7.3 \pm 0.7$ & $11.6 \pm 0.8$ & $16.2 \pm 1.5$ \\
\hline & $\mathrm{CH}+\mathrm{PRP}$ & $9.8 \pm 0.6$ & $9.4 \pm 1.1$ & $16.3 \pm 2.6$ & $25.0 \pm 1.3$ \\
\hline & $P$ & $<0.001$ & $<0.001$ & $<0.001$ & $<0.001$ \\
\hline
\end{tabular}

Data are presented as means \pm SD. CH: chronic hyperglycemia; PRP: platelet-rich plasma; $P$ : possibility by Fisher $F$-criterion. Results of Bonferroni post hoc test are described in the text.

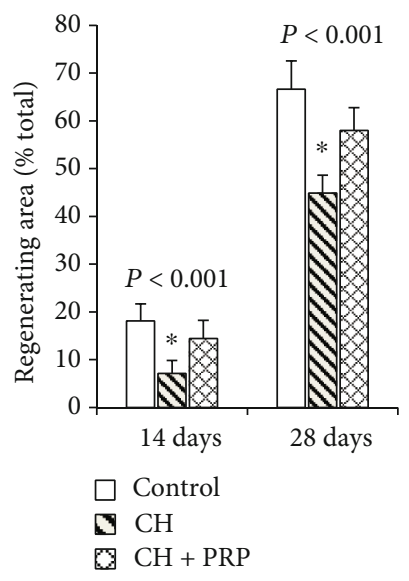

(a)

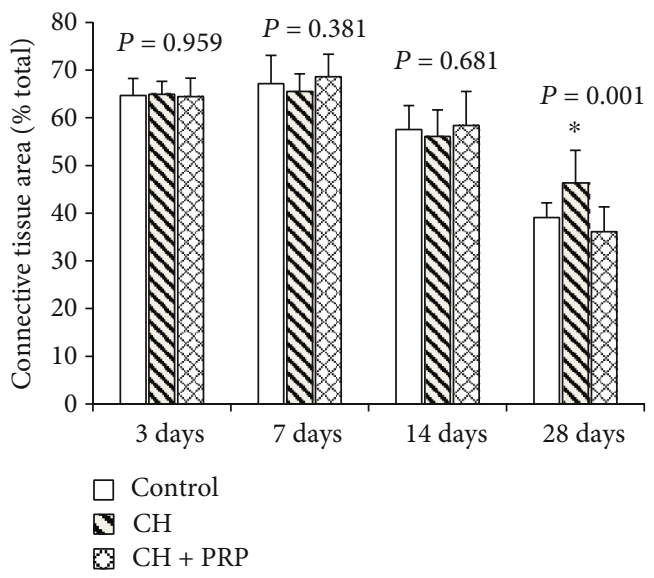

(b)

Figure 1: (a) Percentage regenerating area of total muscle fiber cross-sectional area on the $14^{\text {th }}$ and $28^{\text {th }}$ day after injury. (b) Percentage of connective tissue area of total muscle organ cross-sectional area on the $3^{\text {rd }}, 7^{\text {th }}, 14^{\text {th }}$, and $28^{\text {th }}$ day after injury. ${ }^{*}$ Significant difference by ANOVA.

tissue swelling, blood vessel plethora, and leukocyte infiltration were observed in control rats on the 3rd day after injury (Figure 3(a)). On the 7th day, the large number of fibroblasts and massive collagen fiber formation were detected in the control group (Figure 3(d)). Tissue swelling and leukocyte infiltration were also maintained. On the 14th day, the new muscle fiber formation and significant angiogenesis activation were observed. The slight edema and leukocyte infiltration were also detected. On the 28th day, the histological picture of skeletal muscle recovery in control animals was characterized by fibromuscle regenerate development. There was a massive extracellular matrix formation around CNFs. A significant number of vessel was also observed (Figures 3(g) and $3(\mathrm{j})$ ).

The pattern of muscle regeneration in rats with $\mathrm{CH}$ on the 3rd and 7th day after the muscle injury was mostly similar to control animals. However, relatively small vessel number, lipid accumulation, more pronounced inflammation, and connective tissue development were observed (Figures 3(b) and 3(e)). On the 14th day, tissue swelling and significant leukocyte infiltration in $\mathrm{CH}$ rats were detected. Necrosis sites together with small newly formed fiber number were observed (Figure 3(h)). On the 28th day, there were massive fibrosis and a relatively small number of newly formed vessels in rats with $\mathrm{CH}$. Muscle fibers had a relatively small area. At the same time, inflammatory infiltration persisted (Figure 3(k)).

The histological picture of muscle regeneration in $\mathrm{CH}$ + PRP animals on the 3rd day after lesion mostly corresponded to the $\mathrm{CH}$ group. However, on the 7 th day, edema and leukocyte infiltration were less pronounced and angiogenesis activity was more noticeable in $\mathrm{CH}+\mathrm{PRP}$ rats 

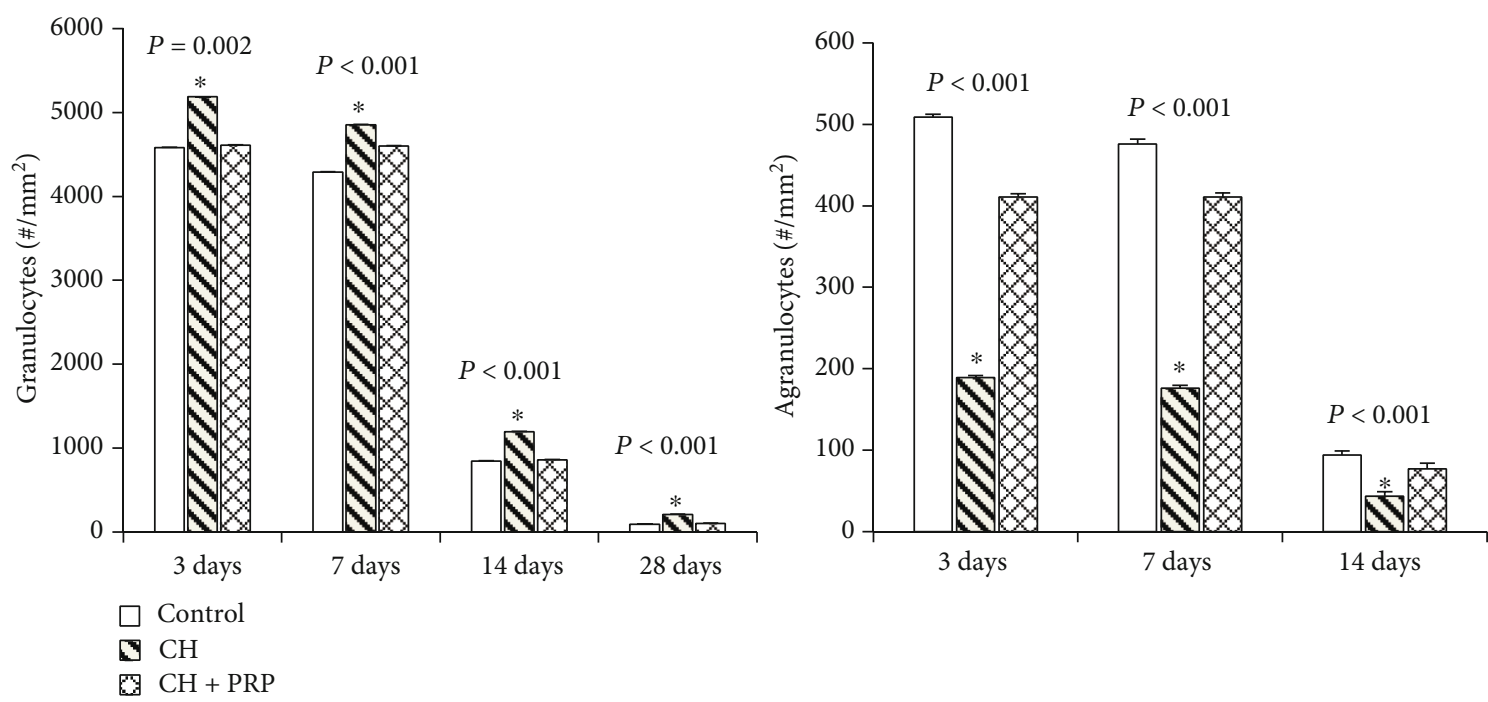

Figure 2: Amount of white blood cells (agranulocytes and granulocytes) in the skeletal muscle on the $3^{\text {rd }}, 7^{\text {th }}, 14^{\text {th }}$, and $28^{\text {th }}$ day after the mechanical injury. Data are presented as means \pm SD. ${ }^{*}$ Significant difference by ANOVA.

compared to animals with $\mathrm{CH}$ (Figures 3(c) and 3(f)). On the 14th day, the massive new muscle fiber formation, blood vessel plethora, and inflammation were detected (Figure 3(i)). On the 28th day, the muscle regeneration process in $\mathrm{CH}+\mathrm{PRP}$ animals was characterized by the large number of new vessels and by massive fibrosis around the CNFs (Figure 3(1)).

A summary of the qualitative assessment of posttraumatic skeletal muscle regeneration in rats of comparison groups is presented in Table 3 .

\section{Discussion}

The structural features of skeletal muscle regeneration in rats with $\mathrm{CH}$, as well as morphological analysis of PRP effect on the striated muscle recovery in animals with $\mathrm{CH}$, were investigated. Mechanical injury by transverse linear incision was used for the experiment. The process of muscle regeneration after the incision had several differences compared to regeneration after injury by chemical agents $[10,26]$, temperature [26], contusion [11], or straining [14]. Necrosis and inflammation prolongation, as well as massive connective tissue development, were observed. Eventually, the regeneration process has culminated in the formation of fibromuscle regenerate. Herewith, after cardiotoxin $[26,27]$ or straining [14] injury, complete skeletal muscle regeneration practically repeats the morphological picture of this organ before the trauma.

Histomorphometric analysis of skeletal muscle regeneration in rats with $\mathrm{CH}$ revealed several salient features. Thus, edema and leukocyte infiltration were observed even 28 days after injury. Herewith, granulocyte predominance and reduced agranulocyte numbers were observed. Similar results were obtained by Krause et al., which showed the decreased macrophage number within regenerating muscles of rats with type 1 DM [9]. Nguyen et al. also have revealed reduced macrophage amount inside skeletal muscle regenerates of rats with a genetic model of type 2 DM [10]. Recent studies have shown that macrophages are the prerequisite for successful skeletal muscle regeneration [28]. Macrophages act as an important regulatory factor in the process of musclespecific cambial cell activation $[29,30]$. Xiao et al. [31] have shown that macrophage depletion leads to excessive connective tissue development and size reduction of newly formed muscle fibers during skeletal muscle regeneration.

Skeletal muscle regeneration in rats with $\mathrm{CH}$ was characterized by significantly reduced new vessel formation, which was also found in animals with a genetic model of type $2 \mathrm{DM}$ [10]. Today, there is no single explanation of angiogenesis impairment within skeletal muscle under $\mathrm{CH}$ condition [32-34]. But it is likely that restricted blood supply due to disrupted neoangiogenesis is an important factor of incomplete posttraumatic muscle regeneration.

$\mathrm{CH}$ inhibits the MyoD and myogenin expression [5] and leads to MSC reduction in the skeletal muscle $[6,7]$. Our results revealed the decrease in amount and total area of newly formed fibers within regenerating striated muscle of rats with $\mathrm{CH}$. Jeong et al. also have shown a significant decrease in CNF number during posttraumatic muscle regeneration in rats with streptozotocin-induced diabetes [8]. In addition, skeletal muscle regeneration in rats with genetic DM models was also associated with a significant decrease in MSC activity and number $[9,10]$.

Skeletal muscle recovery in rats with $\mathrm{CH}$ was characterized also by incompleteness, fat inclusion accumulation, and massive collagen fiber formation, which largely corresponds to results obtained in other similar studies [8-10].

Thus, our results revealed the histopathological signs of $\mathrm{CH}$ negative effect on muscle regeneration in rats with a mechanical muscle injury. Currently, some molecular mechanisms of $\mathrm{CH}$ influence on skeletal muscle repair are described. The experimental DM induces overactivation of myostatin/TGF- $\beta$ receptor signaling, which in turn inhibits the MSC activation, causing poor muscle regeneration [8]. 


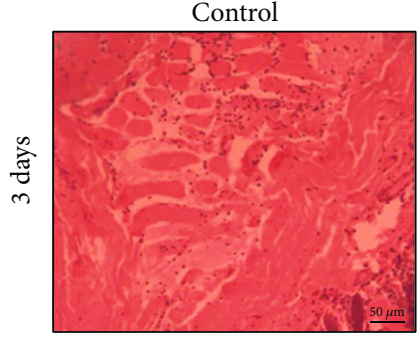

(a)

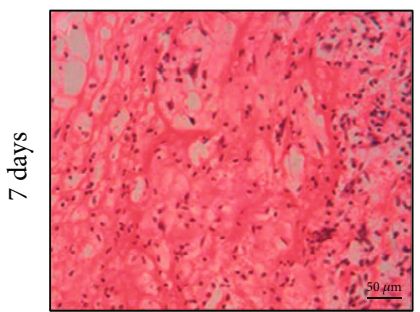

(d)

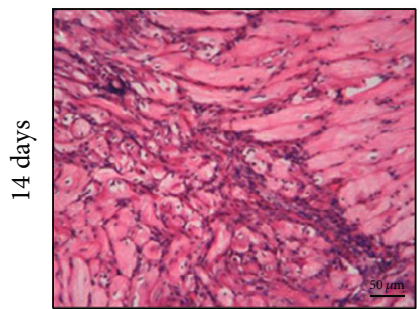

(g)

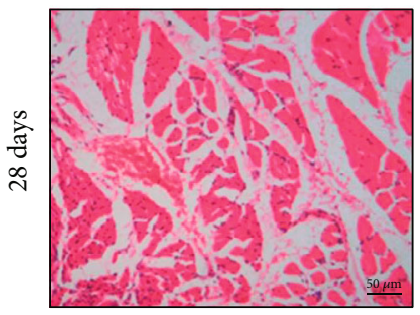

(j)
$\mathrm{CH}$

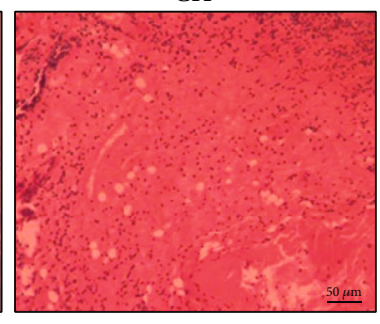

(b)

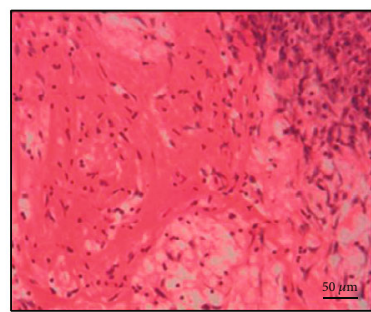

(e)

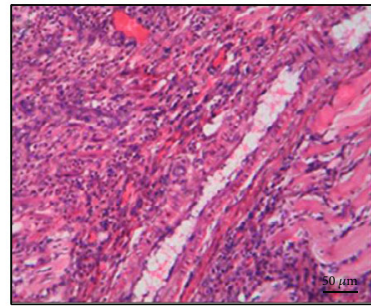

(h)

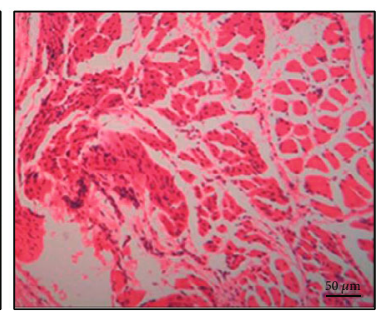

(k)

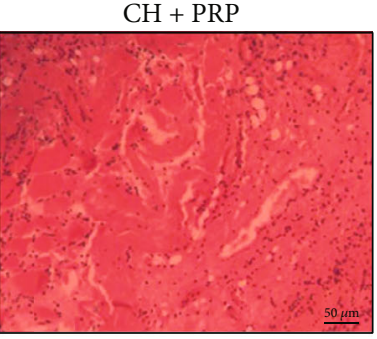

(c)

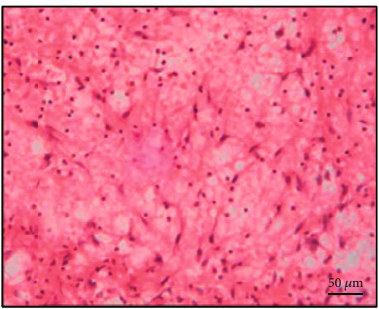

(f)

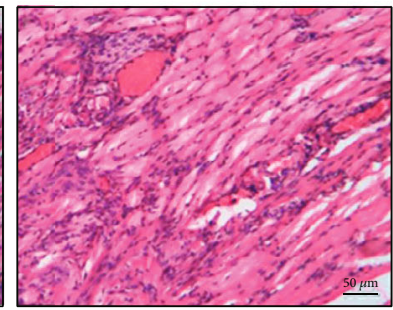

(i)

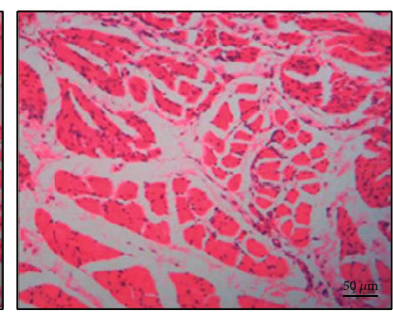

(1)

Figure 3: Histology of skeletal muscle regeneration in control (a, d, g, j), chronic hyperglycemia (b, e, h, k), and chronic hyperglycemia +platelet-rich plasma $(\mathrm{c}, \mathrm{f}, \mathrm{i}, \mathrm{l})$ groups on the $3^{\text {rd }}, 7^{\text {th }}, 14^{\text {th }}$, and $28^{\text {th }}$ day after mechanical injury. Explanations are in the text. Staining-hematoxylin and eosin. Scale bar-50 $\mu \mathrm{m}$.

TABLE 3: Qualitative assessment of skeletal muscle regeneration.

\begin{tabular}{lccccccccccccccc}
\hline & \multicolumn{3}{c}{3 days } & \multicolumn{4}{c}{7 days } & \multicolumn{3}{c}{14 days } & \multicolumn{3}{c}{28 days } \\
& $\mathrm{Ctrl}$ & $\mathrm{CH}$ & $\mathrm{CH}+\mathrm{PRP}$ & $\mathrm{Ctrl}$ & $\mathrm{CH}$ & $\mathrm{CH}+\mathrm{PRP}$ & $\mathrm{Ctrl}$ & $\mathrm{CH}$ & $\mathrm{CH}+\mathrm{PRP}$ & $\mathrm{Ctrl}$ & $\mathrm{CH}$ & $\mathrm{CH}+\mathrm{PRP}$ \\
\hline Necrosis & +++ & +++ & +++ & ++ & +++ & ++ & - & + & & - & - & - & - \\
Connective tissue edema & ++ & +++ & +++ & + & +++ & + & + & ++ & + & - & + & - \\
Inflammatory infiltration & +++ & +++ & +++ & + & +++ & ++ & + & ++ & + & - & + & - \\
Vascularization & ++ & + & ++ & ++ & + & ++ & +++ & ++ & ++ & +++ & ++ & +++ \\
Fibrosis & + & + & + & ++ & ++ & ++ & ++ & ++ & ++ & ++ & +++ & ++ \\
CNFs & - & - & - & + & - & + & ++ & + & ++ & +++ & ++ & +++ \\
\hline
\end{tabular}

Ctrl: control group; $\mathrm{CH}$ : rats with chronic hyperglycemia; $\mathrm{CH}+\mathrm{PRP}$ : rats with chronic hyperglycemia+platelet-rich plasma injection; $\mathrm{CNFs}$ : centrally nucleated fibers. The results are expressed as a percentage of the highest value among all groups: $(-)$ rare or not detected; $(+)$ between $10 \%$ and $30 \%$; (++) between $30 \%$ and $60 \% ;(+++)$ over $60 \%$ 
It was also demonstrated that diabetes results in MSC content and functionality decline due to hyperactivation of the Notch signaling pathway [6]. It is not yet known, whether $\mathrm{CH}$, insulin signaling disruption, or both are the reason for MSC regenerative response impairment. It was also shown that several proinflammatory factors (e.g., interleukin-6 and tumor necrosis factor- $\alpha$ ) are elevated in diabetic patients [35]. This may be a result of advanced glycation end product overformation [36]. Moreover, in vitro experiments revealed that the hyperglycemic environment induces adipogenic differentiation of muscle-derived stem cells [37]. It is assumed that reactive oxygen species and downstream effector kinases, such as PKC- $\beta$, play the main role in this process. All the data, gathered above, can serve as an attempt to substantiate the reduction of new muscle fiber amount, inflammation deregulation, and adipocyte presence in regenerating muscles of rats with streptozotocin-induced $\mathrm{CH}$.

A recent review by Setayesh et al. [38] showed that PRP promotes skeletal muscle regeneration through growth factors secreted from activated platelets. Aydin et al. demonstrated that PRP could improve the histopathological grades in wound healing suppressed by corticosteroid [39]. In addition, a few meta-analyses have shown that topical PRP application for diabetic ulcer treatment accelerates wound healing and significantly reduces the number of complications [22-24]. Given the abovementioned, we have decided to investigate the PRP effect on skeletal muscle regeneration in rats with $\mathrm{CH}$.

The results of the histological analysis showed the difference in severity (leukocyte infiltration, edema presence) and quality (granulocyte and agranulocyte number) of inflammation between the $\mathrm{CH}+\mathrm{PRP}$ group and $\mathrm{CH}$ rats, wherein the results in the $\mathrm{CH}+\mathrm{PRP}$ group were almost the same as in the control. Tsai et al. also demonstrated the reduced amount of CD68-positive and apoptotic cells in the injured skeletal muscle treated with PRP [16]. However, Gigante et al. [12] revealed no difference in the inflammation manifestation during skeletal muscle regeneration between PRP-injected rats and rats without PRP using.

The PRP administration into the skeletal muscle of rats with $\mathrm{CH}$ also resulted in neoangiogenesis activation. The vessel number in the regenerating muscle of $\mathrm{CH}+\mathrm{PRP}$ rats was almost the same as in the control group. The neoangiogenesis intensification during muscular recovery due to PRP using was also revealed by Gigante et al. [12]. The results of our study also showed that PRP contributes to increase of CNF number and total regeneration area in the skeletal muscle of rats with $\mathrm{CH}$. The increase in the number of newly formed fibers during muscle recovery due to PRP injection has also been identified in several studies on animals with different types of mechanical muscle injury [13-15]. These studies also reported collagen area and fibrosis degree reduction in striated muscle regenerates due to PRP administration. Our results also showed that the connective tissue area in $\mathrm{CH}+\mathrm{PRP}$ rats was smaller compared to that in $\mathrm{CH}$ rats.

This is the first report about PRP structural effect on skeletal muscle regeneration in rats with experimental $\mathrm{CH}$. The obtained results revealed that PRP could enhance striated muscle recovery under $\mathrm{CH}$ conditions. However, our research had a few important limitations, which have to be taken into consideration. Firstly, the concentration of growth factors and cytokines was not evaluated in the prepared PRP. Secondly, the immunohistochemistry and confocal microscopy were not used. These would have made the evaluation of the neoangiogenesis nature, as well as the cellular composition of regenerating muscles, much more accurate. Thirdly, no molecular-genetic techniques, such as RT-PCR, have been applied to evaluate the $\mathrm{CH}$ and PRP effect on specific transcription factor expression. Finally, no analysis of dynamic and strength indices of regenerating skeletal muscle were performed, which made it impossible to assess functional recovery in the comparison groups.

\section{Conclusion}

Thus, the streptozotocin-induced $\mathrm{CH}$ has a negative impact on posttraumatic striated muscle regeneration, contributing to massive connective tissue development instead of new muscle fiber formation. The autologous PRP injection promotes the skeletal muscle recovery process in rats with $\mathrm{CH}$, shifting it away from fibrosis toward the complete muscular organ formation.

\section{Data Availability}

The data used to support the findings of this study are available from the corresponding author upon request.

\section{Conflicts of Interest}

There is no conflict of interests regarding the publication of this manuscript.

\section{Acknowledgments}

The study was part of the project "Molecular-genetic and morphological features of lower limb tissue regeneration under chronic hyperglycemia condition," supported by the Ministry of Education and Science of Ukraine (no. 0117U003926).

\section{References}

[1] H. Ge, X. Sun, J. Liu, and C. Zhang, "The status of musculoskeletal disorders and its influence on the working ability of oil workers in Xinjiang, China," International Journal of Environmental Research and Public Health, vol. 15, no. 5, p. 842, 2018.

[2] L. Baoge, E. van den Steen, S. Rimbaut et al., "Treatment of skeletal muscle injury: a review," ISRN Orthopedics, vol. 2012, Article ID 689012, 7 pages, 2012.

[3] J. Liu, D. Saul, K. O. Böker, J. Ernst, W. Lehman, and A. F. Schilling, "Current methods for skeletal muscle tissue repair and regeneration," BioMed Research International, vol. 2018, Article ID 1984879, 11 pages, 2018.

[4] N. G. Forouhi and N. J. Wareham, "Epidemiology of diabetes," Medicine, vol. 42, no. 12, pp. 698-702, 2014. 
[5] M. Aragno, R. Mastrocola, M. G. Catalano, E. Brignardello, O. Danni, and G. Boccuzzi, "Oxidative stress impairs skeletal muscle repair in diabetic rats," Diabetes, vol. 53, no. 4, pp. 1082-1088, 2004.

[6] D. M. D’Souza, S. Zhou, I. A. Rebalka et al., "Decreased satellite cell number and function in humans and mice with type 1 diabetes is the result of altered notch signaling," Diabetes, vol. 65, no. 10, pp. 3053-3061, 2016.

[7] S. Fujimaki, T. Wakabayashi, M. Asashima, T. Takemasa, and T. Kuwabara, "Treadmill running induces satellite cell activation in diabetic mice," Biochemistry and Biophysics Reports, vol. 8, pp. 6-13, 2016.

[8] J. Jeong, M. J. Conboy, and I. M. Conboy, "Pharmacological inhibition of myostatin/TGF- $\beta$ receptor/pSmad3 signaling rescues muscle regenerative responses in mouse model of type 1 diabetes," Acta Pharmacologica Sinica, vol. 34, no. 8, pp. 1052-1060, 2013.

[9] M. P. Krause, D. al-Sajee, D. M. D’Souza et al., "Impaired macrophage and satellite cell infiltration occurs in a musclespecific fashion following injury in diabetic skeletal muscle," PLoS One, vol. 8, no. 8, article e70971, 2013.

[10] M. H. Nguyen, M. Cheng, and T. J. Koh, "Impaired muscle regeneration in ob/ob and db/db mice," ScientificWorldJournal, vol. 11, pp. 1525-1535, 2011.

[11] T. Wright-Carpenter, P. Opolon, H. J. Appell, H. Meijer, P. Wehling, and L. M. Mir, "Treatment of muscle injuries by local administration of autologous conditioned serum: animal experiments using a muscle contusion model," International Journal of Sports Medicine, vol. 25, no. 8, pp. 582-587, 2004.

[12] A. Gigante, M. del Torto, S. Manzotti et al., "Platelet rich fibrin matrix effects on skeletal muscle lesions: an experimental study," Journal of Biological Regulators and Homeostatic Agents, vol. 26, no. 3, pp. 475-484, 2012.

[13] P. Contreras-Muñoz, J. R. Torrella, X. Serres et al., "Postinjury exercise and platelet-rich plasma therapies improve skeletal muscle healing in rats but are not synergistic when combined," The American Journal of Sports Medicine, vol. 45, no. 9, pp. 2131-2141, 2017.

[14] J. W. Hammond, R. Y. Hinton, L. A. Curl, J. M. Muriel, and R. M. Lovering, "Use of autologous platelet-rich plasma to treat muscle strain injuries," The American Journal of Sports Medicine, vol. 37, no. 6, pp. 1135-1142, 2009.

[15] M. L. Quarteiro, J. R. F. Tognini, E. L. F. de Oliveira, and I. Silveira, "The effect of platelet-rich plasma on the repair of muscle injuries in rats," Revista Brasileira de Ortopedia, vol. 50, no. 5, pp. 586-595, 2015.

[16] W. C. Tsai, T. Y. Yu, G. J. Chang, L. P. Lin, M. S. Lin, and J. H. S. Pang, "Platelet-rich plasma releasate promotes regeneration and decreases inflammation and apoptosis of injured skeletal muscle," The American Journal of Sports Medicine, vol. 46, no. 8, pp. 1980-1986, 2018.

[17] M. S. A. Hamid, M. R. M. Ali, A. Yusof, and J. George, "Platelet-rich plasma (PRP): an adjuvant to hasten hamstring muscle recovery. A randomized controlled trial protocol (ISCRTN66528592)," BMC Musculoskeletal Disorders, vol. 13, no. 1, 2012.

[18] A. Nitecka-Buchta, K. Walczynska-Dragon, W. M. Kempa, and S. Baron, "Platelet-rich plasma intramuscular injections antinociceptive therapy in myofascial pain within masseter muscles in temporomandibular disorders patients: a pilot study," Frontiers in Neurology, vol. 10, 2019.
[19] B. H. Hamilton and T. M. Best, "Platelet-enriched plasma and muscle strain injuries: challenges imposed by the burden of proof," Clinical Journal of Sport Medicine, vol. 21, no. 1, pp. 31-36, 2011.

[20] M. S. A. Hamid, A. Yusof, and M. R. M. Ali, "Platelet-rich plasma (PRP) for acute muscle injury: a systematic review," PLoS One, vol. 9, no. 2, article e90538, 2014.

[21] A. Grassi, F. Napoli, I. Romandini et al., "Is platelet-rich plasma (PRP) effective in the treatment of acute muscle injuries? A systematic review and meta-analysis," Sports Medicine, vol. 48, no. 4, pp. 971-989, 2018.

[22] D. L. Villela and V. L. U. C. I. A. C. G. Santos, "Evidence on the use of platelet-rich plasma for diabetic ulcer: a systematic review," Growth Factors, vol. 28, no. 2, pp. 111-116, 2009.

[23] Z. Hu, S. Qu, J. Zhang et al., "Efficacy and safety of platelet-rich plasma for patients with diabetic ulcers: a systematic review and meta-analysis," Advances in Wound Care, vol. 8, no. 7, pp. 298-308, 2019.

[24] T. Hirase, E. Ruff, S. Surani, and I. Ratnani, "Topical application of platelet-rich plasma for diabetic foot ulcers: a systematic review," World Journal of Diabetes, vol. 9, no. 10, pp. 172-179, 2018.

[25] M. R. Messora, M. J. Nagata, F. Furlaneto et al., “A standardized research protocol for platelet-rich plasma (PRP) preparation in rats," RSBO Revista Sul-Brasileira de Odontologia, vol. 8, no. 3, pp. 299-304, 2011.

[26] D. Hardy, A. Besnard, M. Latil et al., "Comparative study of injury models for studying muscle regeneration in mice," PLoS One, vol. 11, no. 1, article e0147198, 2016.

[27] N. Jinno, M. Nagata, and T. Takahashi, "Marginal zinc deficiency negatively affects recovery from muscle injury in mice," Biological Trace Element Research, vol. 158, no. 1, pp. 65-72, 2014.

[28] R. G. Walton, K. Kosmac, J. Mula et al., "Human skeletal muscle macrophages increase following cycle training and are associated with adaptations that may facilitate growth," Scientific Reports, vol. 9, no. 1, p. 969, 2019.

[29] L. C. Ceafalan, T. E. Fertig, A. C. Popescu, B. O. Popescu, M. E. Hinescu, and M. Gherghiceanu, "Skeletal muscle regeneration involves macrophage-myoblast bonding," Cell Adhesion \& Migration, vol. 12, no. 3, pp. 228-235, 2017.

[30] C. Latroche, M. Weiss-Gayet, L. Muller et al., "Coupling between myogenesis and angiogenesis during skeletal muscle regeneration is stimulated by restorative macrophages," Stem Cell Reports., vol. 9, no. 6, pp. 2018-2033, 2017.

[31] W. Xiao, Y. Liu, and P. Chen, "Macrophage depletion impairs skeletal muscle regeneration: the roles of pro-fibrotic factors, inflammation, and oxidative stress," Inflammation, vol. 39, no. 6, pp. 2016-2028, 2016.

[32] R. Cheng and J. X. Ma, "Angiogenesis in diabetes and obesity," Reviews in Endocrine \& Metabolic Disorders, vol. 16, no. 1, pp. 67-75, 2015.

[33] E. Nwadozi, E. Roudier, E. Rullman et al., "Endothelial FoxO proteins impair insulin sensitivity and restrain muscle angiogenesis in response to a high-fat diet," The FASEB Journal, vol. 30, no. 9, pp. 3039-3052, 2016.

[34] S. J. Prior, M. J. Mckenzie, L. J. Joseph et al., "Reduced skeletal muscle capillarization and glucose intolerance," Microcirculation, vol. 16, no. 3, pp. 203-212, 2009.

[35] D. M. D'Souza, D. Al-Sajee, and T. J. Hawke, "Diabetic myopathy: impact of diabetes mellitus on skeletal muscle progenitor cells," Frontiers in Physiology, vol. 4, 2013. 
[36] S. F. Yan, R. Ramasamy, and A. M. Schmidt, "Mechanisms of disease: advanced glycation end-products and their receptor in inflammation and diabetes complications," Nature Clinical Practice. Endocrinology \& Metabolism, vol. 4, no. 5, pp. 285293, 2008.

[37] P. Aguiari, S. Leo, B. Zavan et al., "High glucose induces adipogenic differentiation of muscle-derived stem cells," Proceedings of the National Academy of Sciences of the United States of America, vol. 105, no. 4, pp. 1226-1231, 2008.

[38] K. Setayesh, A. Villarreal, A. Gottschalk, J. M. Tokish, and W. S. Choate, "Treatment of muscle injuries with plateletrich plasma: a review of the literature," Current Reviews in Musculoskeletal Medicine, vol. 11, no. 4, pp. 635-642, 2018.

[39] O. Aydin, G. Karaca, F. Pehlivanli et al., "Platelet-rich plasma may offer a new hope in suppressed wound healing when compared to mesenchymal stem cells," Journal of Clinical Medicine, vol. 7, no. 6, p. 143, 2018. 